\title{
Noam Chomsky: su visión de Colombia
}

\author{
Noam Chomsky: His vision of Colombia
}

El presente artículo es un acercamiento a la vida y obra del connotado pensador Noam Chomsky. Se dedica esta sección de grandes biografías a Noam Chomsky por el carácter político que él representa y que está en coherencia con el dossier de esta publicación. El desarrollo de la Gramática Generativa Transformacional es su primer gran aporte al desarrollo de la ciencia lingüística y pensamiento del siglo XX.

Su visión acerca de las relaciones de los Estados Unidos con los países de Latinoamérica, en general, y con Colombia, en particular constituye la segunda parte de este trabajo, realizado a partir de entrevistas concedidas a medios de comunicación de Colombia.

Palabras clave Chomsky, Colombia, Estados Unidos, lingüística, violentología.

\begin{abstract}
This article is an approach to life and work of the notorious thinker Noam Chomsky. We offer this section of great biographies to Noam Chomsky because of the political role he represents and which is in coherence with the dossier of this publication. The development of Transformational Generative Grammar is his first major contribution to the development of linguistic science and thought of the twentieth century. His vision about U.S. relations with Latin American countries and particularly with Colombia is the second part of this article. This work is possible by some interviews given to the Colombian Media.
\end{abstract}

Keywords Chomsky, Colombia, United States of America, linguistics, violentology.
Neyla Johana-Villarreal*

Docente que avala el artículo:

Jairo Castro Neira ${ }^{* *}$

Recibido: 4 de marzo del 2011

Aprobado: 18 de abril del 2011

Cómo citar este artículo: Villareal, NeylaJohanna (2011), "Noam Chomsky: su visión de Colombia”, en Rastros Rostros, vol. 13, núm. 25, pp. 111-114.

* Estudiante de Licenciatura en Educación Básica con énfasis en Humanidades, Lengua Castellana e Inglés de la Universidad Cooperativa de Colombia, sede Bucaramanga. Correos electrónicos: neilavillarreal@campusucc.edu.co, neilita_villarreal@hotmail.com

** Licenciado en Idiomas de la Universidad Industrial de Santander. Magíster en Semiótica (Tesista) de la Universidad Industrial de Santander. Docente de la Universidad Cooperativa de Colombia, sede Bucaramanga. Correo electrónico:jairo.castro@campusucc.edu.co 
$\mathrm{N}$ oam Chomsky es uno de los más reconocidos intelectuales contemporáneos, nacido en Filadelfia Estados Unidos en 1928.

Su trascendental papel en la evolución del pensamiento se inicia con la propuesta de la Gramática Generativa Transformacional, la cual revolucionó todo el pensamiento lingüístico de la última mitad del siglo XX. Su posición crítica frente a la política internacional de los Estados Unidos es otra faceta de su quehacer intelectual que hace que se le reconozca en todas las latitudes como uno de los más importantes violentólogos de estos tiempos.

La Universidad Nacional de Colombia, en el 2002, le otorgó el doctorado honoris causa por sus aportes al desarrollo de las Ciencias y las Humanidades como lingüista, matemático, filósofo, docente e investigador, el cual se constituye en un reconocimiento a su preocupación permanente por las causas latinoamericanas, en general y por las colombianas, en particular.

\section{El lingüista}

En 1956, Chomsky dio a conocer el libro Estructuras sintácticas (1974), que deja ver el nacimiento de la lingüística moderna, a la vez que el decaimiento del estructuralismo de Leonard Bloomfield. A esta moderna modalidad de la lingüística, se le conoce bajo el nombre de Gramática Generativa Transformacional, la cual se desarrolla a partir de la idea de que el razonamiento lingüístico debe ser tan claro, evidente, riguroso y formal como el razonamiento matemático. Esto lo demuestra con la creación de los árboles generativos, que fragmentan la oración en elementos casi atómicos. Después, da origen al concepto y sistema de transformación, que incluye un complejo juego de reglas de sustituciones que permite al hablante crear una infinidad de oraciones y darles un cambio de nivel gramatical.
Estas reglas se pueden reunir en cinco partes que son: competencia y actuación del hablante-oyente, gramática generativa, estructura profunda y estructura superficial, concepto de transformación, y reglas de rescritura.

La gramática generativa plantea la pregunta: ¿cómo el hablante ha llegado a construir la oración? Según Chomsky: "La competencia del hablanteoyente está constituida por el conocimiento de unos signos y unas reglas que le permiten combinarlos. Aunque el hablante conoce implícitamente las reglas, el gramático las puede hacer explícitas al analizar la secuencia de los signos" (Fuentes, 1998, p. 40). Esto significa que el hablante puede producir oraciones aceptables que se transforman cuando crea un infinito número de ellas con los signos y reglas que conoce previamente. De esta manera, la gramática profunda se vuelve simple con tan sólo cuatro reglas que se conocen bajo el nombre de reglas de escritura:

[...] la primera: la oración se compone de un sintagma nominal más un sintagma predicativo. La segunda: el sintagma nominal se compone de un determinante más un nombre. La tercera: el sintagma predicativo con cópula puede ir acompañado de un sintagma nominal, adjetivo o preposicional. La cuarta: el sintagma predicativo puede ir con un verbo predicativo solo, acompañado de un sintagma nominal, de un sintagma preposicional o de ambos sintagmas (Fuentes, 1998, p. 270).

Estas cuatro reglas conforman la estructura de la Gramática Generativa Transformacional de Chomsky.

Al tener en cuenta todo lo mencionado, se puede decir que la gramática generativa es la que produce cualquier oración entendible y que la gramática transformacional es la que modifica unidades inferiores de lo comprendido por un hablante. 
Sin embargo, se debe recordar que, como estas reglas no son definitivas, los investigadores lingüistas aún están explorando nuevos caminos para rectificar o reafirmar las conclusiones planteadas, o tal vez, como todo está en un constante cambio, para buscar soluciones a preguntas o problemas que no habían sido formulados.

\section{El violentólogo}

En su introducción al libro Colombia: esta democracia genocida, escrito por el padre Javier Giraldo S.J. en 1996, Chomsky expone, a partir de la documentación presentada por el jesuita, su posición frente a la influencia de los Estados Unidos en este país. Relata, por ejemplo, la manera como, encabezados por el país del norte, algunas naciones europeas como Gran Bretaña, Israel y Alemania patrocinaron la llamada "Guerra Sucia”, que sumió al país en el reino del terror durante la década de los ochenta del siglo pasado, respaldados por la idea de que, siendo una democracia, era válido suministrar armas y adiestrar hombres con el pretexto de combatir el narcotráfico, llegando en 1988 a la espeluznante cifra de ocho asesinatos políticos por día.

Las principales víctimas fueron los campesinos, a quienes además les arrasaban sus cosechas y los expulsaban de sus tierras. Pero no sólo eran los campesinos, también eran perseguidos los sindicalistas, los líderes populares, los indígenas, los miembros de los partidos de oposición, los estudiantes, los religiosos y todo aquel que pudiera influenciar o verse influenciado en contra del estado.

En la década de los noventa, en vez de atenuar la situación de violación derechos humanos, se sofistica. Bajo el gobierno de Cesar Gaviria más de 2000 colombianos son adiestrados para la guerra con el patrocinio de la administración Clinton, cuya ayuda alcanzó hasta la mitad del total asignado por Estados Unidos para toda Latinoamérica.
Las desigualdades que se dan en la Colombia son prácticamente las más grandes del mundo. Sólo el 3\% de la población posee más del $70 \%$ de la tierra cultivable y el $40 \%$ de la población vive en condiciones de extrema pobreza; Bienestar Familiar reconoce que la mitad de los niños del país padecen hambre.

Chomsky termina su introducción al libro expresando que resulta alentador que muchos hayan tratado de superar la cultura del miedo. Incluso aquellos que, como el padre Giraldo, usan la palabra como testimonio y terminan siendo una inspiración para actuar.

Catorce años después, en una entrevista publicada por la revista El Malpensante, en diciembre de 2010, el pensador expone claramente sus ideas con respecto a la posición de Estados Unidos frente a América Latina, las cuales son ahora más o menos optimistas. Afirma que después de doscientos años en los que Latinoamérica no ha podido desarrollarse plenamente debido a problemas como la falta de integración, las tremendas desigualdades sociales y el surgimiento de movimientos indígenas orientados hacia la defensa de sus derechos y tradiciones, se puede hablar ahora de esperanzas latinoamericanas, a pesar del caudillismo y de las imperfectas estructuras sociales.

De Venezuela, por ejemplo, piensa que a pesar de los grandes problemas de violencia, corrupción y autoritarismo, se han conseguido avances en contra de la pobreza que pueden ser positivos si se mantienen en el tiempo. En Bolivia, cree que los cambios se han venido dando, al contrario que en Venezuela, de abajo a arriba de la pirámide social.

Acerca de lo que sucede en Colombia, está al tanto de los movimientos sociales en contra de la explotación minera que contamina las fuentes de agua y de la aparente intención del gobierno de privatizarla. Espera que el gobierno de Santos sea, debido a que su extracción social es distinta a la de

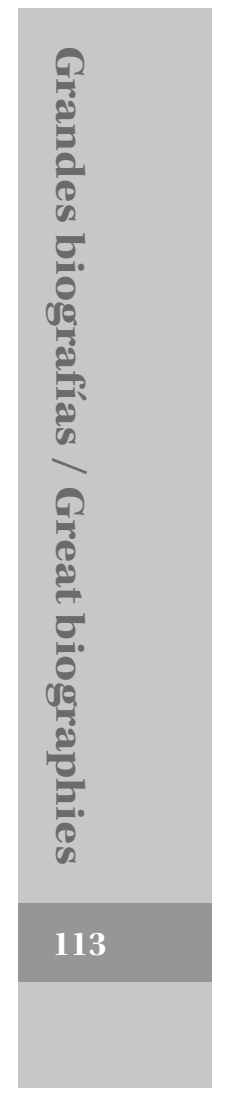

Revista Rastros Rostros - Volumen 13, Número 25 - enero-junio 2011 
Álvaro Uribe, en lo que tiene que ver con los derechos humanos, menos brutal y en lo que tiene que ver con el diálogo, más abierto. En cuanto al problema de la instalación de bases militares de Estados Unidos en el país, cree que este hecho está en contra de la integración latinoamericana, la cual es prerrequisito para una independencia real.

Es Noam Chomsky definitivamente un conocedor de la situación política y social latinoamericana, y en lo que tiene que ver con Colombia, además, un hombre comprometido con su futuro, del que advierte que para alcanzarlo falta todavía un largo camino que recorrer.

\section{Referencias}

Chomsky, N. (1956), Estructuras sintácticas, México, Siglo XXI.

Fuentes de la Corte, J. L. (1998), Gramática Moderna de la Lengua Española, Limusa, México.

Giraldo, J. (1994), "Colombia: esta democracia genocida”, Cuaderno 61, Cristianisme i Justicia, Barcelona.

Muñoz, B. (2010, diciembre), "Esperanzas latinoamericanas”, en Revista El Malpensante [en línea], disponible en: http://www.elmalpensante.com/index. php?doc=display_contenido\&id=1727\&pag=3\&size $=\mathrm{n}$ 